\title{
VOLUMES DE CALDA E PONTAS DE PULVERIZAÇÃo NO CONTROLE QUÍMICO DE Spodoptera frugiperda NA CULTURA DO SORGO FORRAGEIRO
}

\author{
JOÃO P. A. R. DA CUNHA ${ }^{1}$, ADEMILSON D. DA SILVA JÚNIOR ${ }^{2}$
}

\begin{abstract}
RESUMO: No manejo de Spodoptera frugiperda na cultura do sorgo, a utilização de inseticida ainda é a principal tática recomendada, contudo este método de controle precisa ser otimizado. $\mathrm{O}$ presente trabalho teve como objetivo avaliar o efeito da utilização de três pontas e dois volumes de calda na aplicação de inseticida para o controle químico de Spodoptera frugiperda na cultura do sorgo. O ensaio foi conduzido no delineamento em blocos ao acaso, com quatro repetições, em esquema fatorial $(3 \times 2)+1$ : três tipos de pontas de pulverização (jato cônico vazio, jato plano defletor duplo e jato plano defletor com indução de ar), dois volumes de calda (200 e $\left.130 \mathrm{~L} \mathrm{ha}^{-1}\right)$ e um tratamento adicional que não recebeu inseticida. Realizou-se a semeadura direta de uma cultivar de sorgo forrageiro, avaliando-se, após a aplicação do inseticida clorpirifós, a deposição de calda no dossel da cultura, o controle de Spodoptera frugiperda e a produtividade. Pôde-se concluir que as pontas de jato plano defletor duplo e jato plano defletor com indução de ar proporcionaram maior cobertura do dossel das plantas de sorgo do que a ponta de jato cônico, resultando em maior eficácia de controle de Spodoptera frugiperda e maior produtividade. O volume de calda de $200 \mathrm{~L} \mathrm{ha}^{-1}$, quando comparado ao volume de $130 \mathrm{~L} \mathrm{ha}^{-1}$, também proporcionou melhor eficácia de controle.
\end{abstract}

PALAVRAS-CHAVE: tecnologia de aplicação, bicos de pulverização, lagarta-do-cartucho, Sorghum bicolor.

\section{SPRAY VOLUME AND SPRAY NOZZLE EFFECTS ON CHEMICAL CONTROL OF Spodoptera frugiperda IN FODDER SORGHUM}

\begin{abstract}
In the management of Spodoptera frugiperda in sorghum, the insecticide use is the main tool recommended, but this method needs to be optimized. The objective of this work was to evaluate the spray volume and spray nozzle effects on chemical control of Spodoptera frugiperda in sorghum. A randomized complete-block design with four replications was used, in a factorial model $(3 \times 2)+1$ : three spray nozzles (hollow cone, turbo twin flat-fan and air induction turbo flat-fan), two spray volumes (200 and $130 \mathrm{~L} \mathrm{ha}^{-1}$ ) and the control (non-treated plot). Fodder sorghum was sown and after the application of the insecticide chlorpirifos, the spray deposition in the plant canopy, the Spodoptera frugiperda control, and the yield were evaluated. The results showed that the turbo twin flat-fan and the air induction turbo flat-fan nozzles provided better canopy coverage than the hollow cone, resulting in a good control of Spodoptera frugiperda and increase of yield. The spray volume of $200 \mathrm{~L} \mathrm{ha}^{-1}$ when compared to the $130 \mathrm{~L} \mathrm{ha}^{-1}$ propitiated also better control.
\end{abstract}

KEYWORDS: application technology, spray nozzles, fall armyworm, Sorghum bicolor.

\section{INTRODUÇÃO}

Considerada uma das alternativas para a alimentação animal, a cultura do sorgo (Sorghum bicolor (L.) Moench.) forrageiro tem papel importante por sua capacidade de adaptação à seca, fator limitante à cultura do milho, garantindo melhores resultados econômicos à atividade (NASCIMENTO et al., 2008). Contudo, apesar do alto potencial produtivo da cultura de sorgo e da grande disponibilidade de cultivares com características que possibilitam a sua adequação às diferentes regiões, observa-se, muitas vezes, produção baixa e irregular (GONTIJO NETO et al.,

\footnotetext{
${ }^{1}$ Eng ${ }^{\circ}$ Agrícola, Prof. Doutor, Instituto de Ciências Agrárias, Universidade Federal de Uberlândia, Uberlândia - MG, Fone: (0XX34) 3218-2226,jpcunha@iciag.ufu.br.

${ }^{2}$ Eng $^{\mathrm{o}}$ Agrônomo, Instituto de Ciências Agrárias, Universidade Federal de Uberlândia, Uberlândia - MG, ademilsontx@bol.com.br.

Recebido pelo Conselho Editorial em: 11-11-2009

Aprovado pelo Conselho Editorial em: 20-5-2010
}

Eng. Agríc., Jaboticabal, v.30, n.4, p.692-699, jul./ago. 2010 
2002). Nesse aspecto, considera-se que o não controle de pragas e patógenos seja um dos fatores responsáveis pela baixa produtividade nas áreas destinadas à produção de silagem.

No mundo, o número de espécies de insetos registradas que atacam a cultura do sorgo é extenso, no entanto apenas algumas trazem danos econômicos, como a lagarta-do-cartucho Spodoptera frugiperda (J. E. Smith, 1797) (Lepidoptera: Noctuidae) (AZEVEDO et al., 2004). Seus danos típicos são as raspagens das folhas e a destruição do cartucho. Como consequência do ataque, em muitos casos, faz-se necessário o uso da aplicação de inseticidas em quantidade e estágios de desenvolvimento ideais, principalmente em híbridos mais suscetíveis. Os danos causados pela praga nas fases vegetativa e reprodutiva do sorgo variam de acordo com o estádio fenológico da planta, condições edafoclimáticas, sistemas de cultivo e fatores bióticos localizados.

Os resultados das aplicações de agrotóxicos nas lavouras, no entanto, são variáveis. O grau de sucesso geralmente é determinado pela quantidade e uniformidade da cobertura. A aplicação de agrotóxicos é uma ferramenta valiosa na agricultura, quando baseada em critérios técnicos bem definidos. Não basta conhecer o produto a ser aplicado, sendo também fundamental conhecer a forma de aplicação. É preciso garantir que o produto alcance eficientemente o alvo, proporcionando menores perdas e contribuindo de forma positiva para o aumento da produtividade (CUNHA et al., 2006).

Uma das formas de se obter maior deposição do ingrediente ativo sobre alvos biológicos é a seleção correta das pontas de pulverização (CUNHA et al., 2008). Essas pontas são os componentes mais significativos dos pulverizadores, afetando diretamente a eficiência do processo de aplicação de agroquímicos (NUYTTENS et al., 2007). Outra variável importante na aplicação de inseticidas é o volume de calda, sendo que, atualmente, existe tendência em reduzir esse volume (BOLLER \& MACHRY, 2007), de forma a aumentar a capacidade operacional dos pulverizadores e reduzir os custos de produção. Contudo, essa redução de volume requer otimização da tecnologia de aplicação para assegurar a manutenção da eficiência das aplicações.

Dessa forma, o presente trabalho teve como objetivo avaliar o efeito da utilização de três pontas e dois volumes de calda na aplicação de inseticida para o controle químico de Spodoptera frugiperda na cultura do sorgo.

\section{MATERIAL E MÉTODOS}

O presente trabalho foi conduzido na Fazenda Experimental do Glória, pertencente à Universidade Federal de Uberlândia, localizada no município de Uberlândia - MG. Realizou-se a semeadura direta da cultivar de sorgo Volumax, na safra de 2008/2009, utilizando-se do espaçamento entre fileiras de $0,8 \mathrm{~m}$ e 10 plantas por metro.

O ensaio foi conduzido no delineamento em blocos ao acaso, com quatro repetições, em esquema fatorial $(3 \times 2)+1$ : três tipos de pontas de pulverização (jato cônico vazio, jato plano defletor duplo e jato plano defletor com indução de ar), dois volumes de calda $\left(200\right.$ e $\left.130 \mathrm{~L} \mathrm{ha}^{-1}\right)$ e um tratamento adicional que não recebeu inseticida (testemunha). As parcelas experimentais foram compostas de quatro linhas de cinco metros de comprimento.

Utilizou-se o inseticida Lorsban $480 \mathrm{BR}$, do grupo químico organofosforado, na formulação concentrado emulsionável, composto pela mistura de clorpirifós + ingredientes inertes $\left(480 \mathrm{~g} \mathrm{~L}^{-1}+\right.$ $669 \mathrm{~g} \mathrm{~L}^{-1}$ ), na dose de $0,5 \mathrm{~L} \mathrm{ha}^{-1}$ de produto comercial. A aplicação foi realizada utilizando-se de um pulverizador costal de pressão constante $\left(\mathrm{CO}_{2}\right)$, dotado de uma barra com disposição simultânea de quatro bicos espaçados de $0,5 \mathrm{~m}$. O momento da pulverização foi determinado pelo nível de controle (10\% das folhas raspadas pela Spodoptera frugiperda).

Empregou-se a pressão de $200 \mathrm{kPa}$, para as pontas de jato plano, e $400 \mathrm{kPa}$, para a ponta de jato cônico, e velocidade de deslocamento de $4 \mathrm{~km} \mathrm{~h}^{-1}$, para o volume de calda de $200 \mathrm{~L} \mathrm{ha}^{-1}$, e $6 \mathrm{~km} \mathrm{~h}^{-1}$, para o volume de $130 \mathrm{~L} \mathrm{ha}^{-1}$. A altura de aplicação em relação à cultura foi de $0,5 \mathrm{~m}$. Utilizaram-se pontas de pulverização hidráulicas, conforme especificado na Tabela 1. 
TABELA 1. Tipos de pontas de pulverização utilizadas. Spray nozzle specifications.

\begin{tabular}{lccc}
\hline \multicolumn{1}{c}{ Ponta } & Descrição & Fabricante & DMV* \\
\hline JA 2 & Jato cônico vazio & Jacto & $153 \mu \mathrm{m}(414 \mathrm{kPa})$ \\
TTJ60 110-02 & Jato plano defletor duplo & Teejet & $284 \mu \mathrm{m}(200 \mathrm{kPa})$ \\
TTI 110-02 & $\begin{array}{c}\text { Jato plano defletor com } \\
\text { indução de ar }\end{array}$ & Teejet & $925 \mu \mathrm{m}(200 \mathrm{kPa})$ \\
\hline
\end{tabular}

*Diâmetro da mediana volumétrica indicado pelo fabricante. O número entre parênteses indica a pressão de trabalho testada pelo fabricante para o DMV fornecido.

A avaliação da eficácia dos tratamentos no controle de Spodoptera frugiperda foi feita mediante a contagem (levantamentos) do número de lagartas antes e depois da aplicação, além da avaliação final da produtividade $\left(\mathrm{kg}\right.$ de matéria seca ha $\left.{ }^{-1}\right)$ entre parcelas tratadas com o inseticida e parcelas não tratadas (testemunha). Também foi conduzido o estudo de deposição da calda do inseticida pulverizado, considerando as parcelas que receberam produto, por meio da análise de papéis hidrossensíveis.

As amostragens foram realizadas aos 45 dias após a emergência (DAE), antes da aplicação do inseticida, e aos 47 e 50 DAE, correspondendo a dois e cinco dias após a aplicação, por meio da contagem do número de lagartas existentes no cartucho da cultura. Na avaliação da infestação, marcaram-se dez plantas, escolhidas ao acaso em cada parcela e, em cada planta, realizou-se o levantamento do número de lagartas. As médias dessas avaliações constituíram a infestação média da praga por parcela.

A porcentagem de eficácia dos tratamentos foi calculada pela fórmula de HENDERSON \& TILTON (1955), esquematizada na eq.(1):

$$
E=\left[1-\left(\frac{T a}{T d} \frac{\mathrm{td}}{\mathrm{ta}}\right)\right] 100
$$

em que,

E - eficácia, \%;

Ta - número de insetos vivos na testemunha antes da aplicação;

Td - número de insetos vivos na testemunha depois da aplicação;

td - número de insetos vivos no tratamento depois da aplicação, e

ta - número de insetos vivos no tratamento antes da aplicação.

Os valores obtidos foram, então, classificados segundo os critérios de baixa eficácia (menor que $80 \%$ ), boa eficácia (de 80 a 90\%) e alta eficácia (maior que 90\%).

A colheita foi realizada ao final do ciclo da cultura, e a avaliação da produtividade (kg de matéria seca $\mathrm{ha}^{-1}$ ) foi feita colhendo-se, de cada parcela, duas linhas com 3,0 m de comprimento cada. As plantas foram retiradas, trituradas, secas em estufa de ventilação forçada $\left(72\right.$ horas a $\left.65^{\circ} \mathrm{C}\right)$ e pesadas.

A deposição de gotas no dossel do sorgo foi determinada por meio da contagem dos impactos em papel hidrossensível (76 x $26 \mathrm{~mm}$ ). Antes da pulverização, foram marcadas quatro plantas ao acaso em cada parcela e, em cada planta, foram colocados dois papéis: um na parte superior e outro na parte inferior da planta, ambos na parte adaxial da folha. Após a aplicação, os papéis foram retirados e digitalizados (resolução espacial de 600 dpi não interpolados, com cores em 24 bits), sendo submetidas à análise de imagens por meio da utilização do programa computacional CIR 1.5 (Conteo Y Tipificación de Impactos de Pulverización). Esse programa utiliza o fator de espalhamento recomendado pelo fabricante dos papéis hidrossensíveis (Syngenta). Foram determinados o número de gotas por centímetro quadrado e a percentagem de cobertura.

Durante a aplicação do inseticida, foram monitoradas as condições ambientais de temperatura, umidade relativa do ar e velocidade do vento. Os dados obtidos foram submetidos primeiramente 
aos testes de normalidade de Shapiro Wilk e homogeneidade das variâncias de Levene e, posteriormente, à análise de variância. As médias das parcelas tratadas com inseticidas foram comparadas entre si, utilizando-se do teste de Tukey, a 5\% de probabilidade, e com a testemunha, no caso da produtividade, utilizando-se do teste de Dunnett, a 5\% de probabilidade. Os dados de eficácia foram transformados em raiz quadrada de $(x+0,5)$.

\section{RESULTADOS E DISCUSSÃO}

A temperatura, a umidade relativa do ar e a velocidade do vento foram favoráveis durante as aplicações do inseticida: temperatura inferior a $27^{\circ} \mathrm{C}$, umidade relativa superior a $60 \%$ e velocidade do vento entre 4 e $7 \mathrm{~km} \mathrm{~h}^{-1}$.

$\mathrm{Na}$ Tabela 2, apresentam-se as médias das densidades de gotas depositadas nas partes superior e inferior do dossel da cultura do sorgo, após a aplicação do inseticida. Não houve interação entre pontas e volumes de calda, indicando a independência entre os dois fatores. Tanto na posição superior, como na inferior, houve diferença significativa entre as médias de gotas depositadas, sendo que, nas duas posições, os tratamentos com menor volume de calda $\left(130 \mathrm{~L} \mathrm{ha}^{-1}\right)$ e com a ponta de jato plano defletor com indução de ar apresentaram menor deposição. Em contrapartida, os tratamentos com maior volume $\left(200 \mathrm{~L} \mathrm{ha}^{-1}\right)$ e com ponta de jato cônico vazio apresentaram maior densidade de gotas depositadas.

As pontas de jato cônico vazio apresentam gotas de menor diâmetro em relação às demais (Tabela 1), resultando em um maior número de impactos por área. Segundo CUNHA et al. (2004), essa ponta proporciona maior densidade de gotas depositadas sobre o alvo, para um mesmo volume de aplicação. No entanto, há risco de contaminação ambiental em função da deriva e, por isso, têm-se buscado alternativas que minimizem tais problemas.

TABELA 2. Densidade de gotas depositadas $\left(\right.$ gotas $\mathrm{cm}^{-2}$ ) nas partes superior e inferior do dossel da cultura do sorgo, após a aplicação de inseticida com diferentes pontas de pulverização, em dois volumes de calda. Droplet density (droplets $\mathbf{c m}^{-2}$ ) on top and lower sorghum canopy, after insecticide application with different nozzles, in two spray volumes.

\begin{tabular}{|c|c|c|c|c|c|c|}
\hline \multirow{3}{*}{ Ponta } & \multicolumn{3}{|c|}{ Gotas $\mathrm{cm}^{-2}$ - Posição Superior } & \multicolumn{3}{|c|}{ Gotas $\mathrm{cm}^{-2}$ - Posição Inferior } \\
\hline & \multicolumn{2}{|c|}{ Volume de Calda (L ha $\left.{ }^{-1}\right)$} & \multirow{2}{*}{ Média } & \multicolumn{2}{|c|}{ Volume de Calda $\left(\mathrm{L} \mathrm{ha}^{-1}\right)$} & \multirow{2}{*}{ Média } \\
\hline & 130 & 200 & & 130 & 200 & \\
\hline JA 2 & 301 & 393 & $347 a$ & 207 & 288 & $248 \mathrm{a}$ \\
\hline TTJ60 110-02 & 267 & 330 & $299 b$ & 197 & 238 & $218 b$ \\
\hline TTI 110-02 & 190 & 250 & $220 c$ & 132 & 154 & $143 \mathrm{c}$ \\
\hline Média & 253B & $324 \mathrm{~A}$ & & 179B & $226 \mathrm{~A}$ & \\
\hline
\end{tabular}

Médias seguidas por letras distintas maiúsculas, nas linhas, e minúsculas, nas colunas, para cada aplicação, diferem significativamente entre si, a 5\% de probabilidade, pelo teste F, e a 5\% pelo teste de Tukey, respectivamente.

Pode-se verificar, pela Tabela 3, que as médias de cobertura das gotas nas partes superior e inferior do dossel da cultura do sorgo, após a aplicação de inseticida, não diferiram entre si, em relação aos volumes de calda. Porém, houve diferença em relação ao uso das diferentes pontas. A maior cobertura foi obtida com a ponta TTI 110-02, e a menor, com a ponta JA 2. Esse resultado, a princípio, contraria o mostrado na Tabela 2, contudo os dados de impacto de gotas por unidade de área devem ser sempre analisados em conjunto com o tamanho das gotas. Assim, a ponta de indução de ar, mesmo com menor número de impactos, em virtude do maior tamanho de gotas $(\mathrm{DMV}=925 \mu \mathrm{m})$, apresentou maior cobertura, variável essa mais importante que o número de impactos para o estabelecimento da eficácia do produto no controle das pragas do sorgo. Além disso, a evaporação e a deriva das gotas menores, presentes principalmente na ponta de jato cônico vazio, podem ter colaborado para o resultado apresentado. 
Resultados semelhantes foram encontrados por CUNHA et al. (2008), avaliando a deposição de fungicida na cultura da soja. Já ponta TTJ60 110-02 não se diferenciou significativamente das demais quanto à cobertura.

Em trabalho realizado por ZHU et al. (2004), estudando a penetração da pulverização proporcionada por diferentes pontas na cultura do amendoim, os autores também mostraram o potencial de uso das pontas de indução de ar no que se refere à cobertura do alvo. Nesse trabalho, as pontas de jato plano duplo e jato plano com indução de ar promoveram maior cobertura do alvo quando comparado à ponta de jato cônico vazio.

Ainda segundo os autores, as pontas de indução de ar geram gotas de maior tamanho que, por isso, têm maior facilidade de alcançar o alvo, principalmente na parte inferior das culturas. Além disso, o fato de as gotas conterem ar em seu interior, faz com que a mesmas apresentem um impacto diferenciado no alvo, resultando em maior cobertura. Contudo, esse processo de contato da gota gerada por uma ponta de indução de ar com o alvo ainda é pouco conhecido e estudado.

TABELA 3. Cobertura de gotas depositadas (\%) nas partes superior e inferior do dossel da cultura do sorgo, após a aplicação de inseticida com diferentes pontas de pulverização, em dois volumes de calda. Droplet coverage $(\%)$ on top and lower sorghum canopy, after insecticide application with different nozzles, in two spray volumes.

\begin{tabular}{|c|c|c|c|c|c|c|}
\hline \multirow{3}{*}{ Ponta } & \multicolumn{3}{|c|}{ Cobertura (\%) - Posição Superior } & \multicolumn{3}{|c|}{ Cobertura (\%) - Posição Inferior } \\
\hline & \multicolumn{2}{|c|}{ Volume de Calda (L ha $\left.{ }^{-1}\right)$} & \multirow{2}{*}{ Média } & \multicolumn{2}{|c|}{ Volume de Calda $\left(\mathrm{L} \mathrm{ha}^{-1}\right)$} & \multirow{2}{*}{ Média } \\
\hline & 130 & 200 & & 130 & 200 & \\
\hline JA 2 & 13,5 & 18,7 & $16,1 b$ & 16,2 & 15,0 & $15,6 b$ \\
\hline TTJ60 110-02 & 18,5 & 20,8 & $19,7 \mathrm{ab}$ & 16,7 & 21,7 & $19,2 \mathrm{ab}$ \\
\hline TTI 110-02 & 29,3 & 31,2 & $30,3 \mathrm{a}$ & 21,5 & 23,0 & $22,3 \mathrm{a}$ \\
\hline Média & $20,4 \mathrm{~A}$ & $23,6 \mathrm{~A}$ & & $18,1 \mathrm{~A}$ & $19,9 \mathrm{~A}$ & \\
\hline
\end{tabular}

Médias seguidas por letras distintas maiúsculas, nas linhas, e minúsculas, nas colunas, para cada aplicação, diferem significativamente entre si, a $5 \%$ de probabilidade, pelo teste $\mathrm{F}$, e a $5 \%$ pelo teste de Tukey, respectivamente.

Na Tabela 4, está apresentada a eficácia de controle de Spodoptera frugiperda dois e cinco dias após a aplicação do inseticida. Aos dois dias após a aplicação, nota-se que não houve diferença significativa entre os volumes utilizados, contudo as pontas TTI 110-02 e TTJ60 110-02 apresentaram melhores resultados. Já aos cinco dias após a aplicação, percebeu-se diferença significativa entre os volumes utilizados, sendo que o melhor volume foi o de $200 \mathrm{~L} \mathrm{ha}^{-1}$. Novamente, a ponta de jato cônico vazio apresentou baixa eficácia de controle. Esses resultados podem ser advindos da cobertura $(\%)$ do inseticida na planta. Boa eficácia de controle em geral está associada à boa cobertura do alvo.

SILVA (1999), estudando a eficiência de inseticidas sobre Spodoptera frugiperda em milho com volumes de calda de 150 e $300 \mathrm{~L} \mathrm{ha}^{-1}$, também concluiu que maiores volumes de pulverização são mais indicados para o controle desta praga. $\mathrm{O}$ autor afirma ainda que, quando se utilizam pontas de jato cônico, com interior oco, os inseticidas são menos eficientes do que aplicações com jato plano dirigido ao cartucho da planta (local de ataque da praga), explicando também a melhor eficiência de controle com a utilização das pontas TTI 110-02 e TTJ60 110-02 em relação à JA 2.

Segundo a classificação de HENDERSON \& TILTON (1955), aos dois após a aplicação, todos os tratamentos apresentaram baixa eficácia $(<80 \%)$, diferentemente da avaliação feita aos cinco dias, onde se comprovou boa eficácia (>80\%) empregando-se as pontas TTJ60 110-02 e TTI 110-02 e uma baixa eficácia com a ponta JA 2. 
TABELA 4. Eficácia de controle (\%) de Spodoptera frugiperda dois e cinco dias após a aplicação (DAA) de inseticida com diferentes pontas de pulverização, em dois volumes de calda. Efficacy (\%) of Spodoptera frugiperda control in sorghum, two and five days after the insecticide application with different nozzles, in two spray volumes.

\begin{tabular}{lcccccc}
\hline \multirow{2}{*}{ Ponta } & \multicolumn{3}{c}{ Eficácia - 2 DAA (\%) } & \multicolumn{3}{c}{ Eficácia - 5 DAA (\%) } \\
\cline { 2 - 3 } & \multicolumn{2}{c}{ Volume de Calda $\left(\mathrm{L} \mathrm{ha}^{-1}\right)$} & \multirow{2}{*}{ Média } & \multicolumn{2}{c}{ Volume de Calda $\left(\mathrm{L} \mathrm{ha}^{-1}\right)$} & \multirow{2}{*}{ Média } \\
\cline { 2 - 3 } \cline { 5 - 7 } & 130 & 200 & & 130 & 200 & \\
\hline JA 2 & 56,0 & 62,3 & $59,2 \mathrm{~b}$ & 71,8 & 83,3 & $77,6 \mathrm{~b}$ \\
TTJ60 110-02 & 70,8 & 77,8 & $74,3 \mathrm{a}$ & 87,0 & 87,5 & $87,3 \mathrm{a}$ \\
TTI 110-02 & 80,0 & 78,5 & $79,3 \mathrm{a}$ & 87,5 & 91,0 & $89,3 \mathrm{a}$ \\
\hline Média & $68,9 \mathrm{~A}$ & $72,9 \mathrm{~A}$ & & $82,1 \mathrm{~B}$ & $87,3 \mathrm{~A}$ & \\
\hline
\end{tabular}

Médias seguidas por letras distintas maiúsculas, nas linhas, e minúsculas, nas colunas, para cada aplicação, diferem significativamente entre si, a 5\% de probabilidade, pelo teste $\mathrm{F}$, e a $5 \%$ pelo teste de Tukey, respectivamente.

$\mathrm{Na}$ Tabela 5, tem-se o efeito dos tipos de ponta e dos volumes de calda, utilizados na aplicação de inseticida em relação à produtividade do sorgo. Nota-se diferença significativa entre os volumes utilizados, sendo que o volume de $200 \mathrm{~L} \mathrm{ha}^{-1}$ proporcionou maior produtividade. Em relação às pontas, também houve diferença significativa, a qual mostrou que as pontas de jato plano defletor duplo e jato plano defletor com indução de ar foram mais eficientes no controle da lagarta, resultando em maior produtividade. Percebe-se também que houve correlação entre cobertura do alvo, eficácia de controle e produtividade: tratamentos que propiciaram maior cobertura resultaram em maior controle e maior produtividade. SERRA et al. (2008) afirmam que, quanto maior a quantidade de produto depositada na superfície de forma homogênea, maior poderá ser a sua ação.

TABELA 5. Efeito do volume de calda e do tipo de ponta, utilizados na pulverização de inseticida, na produtividade do sorgo ( $\mathrm{kg}$ de matéria seca $\mathrm{ha}^{-1}$ ). Effects of spray volume and nozzles, used in insecticide application, on sorghum yield ( $\mathrm{kg}$ of dry matter ha ${ }^{-1}$ ).

\begin{tabular}{lccc}
\hline \multirow{2}{*}{ Ponta } & \multicolumn{3}{c}{ Produtividade $\left(\mathrm{kg} \mathrm{ha}^{-1}\right)$} \\
\cline { 2 - 3 } & \multicolumn{2}{c}{ Volume de Calda $\left(\mathrm{L} \mathrm{ha}^{-1}\right)$} & \multirow{2}{*}{ Média } \\
\cline { 2 - 3 } & 130 & 200 & $15.422,6 \mathrm{~b}$ \\
JA 2 & $16.460,8$ & $15.384,3$ & $16.587,2 \mathrm{a}$ \\
TTJ60 110-02 & $16.266,8$ & $16.651,8$ & $16.660,6 \mathrm{a}$ \\
TTI 110-02 & $16.083,4 \mathrm{~B}$ & $17.054,5$ & \\
\hline Média & $16.363,5 \mathrm{~A}$ & \\
\hline
\end{tabular}

Médias seguidas por letras distintas maiúsculas, nas linhas, e minúsculas, nas colunas, para cada aplicação, diferem significativamente entre si, a 5\% de probabilidade, pelo teste $\mathrm{F}$, e a 5\% pelo teste de Tukey, respectivamente.

Na Tabela 6, tem-se o efeito da aplicação de inseticida na produtividade comparado à testemunha que não recebeu produto. A produtividade do sorgo foi superior à testemunha em todas as parcelas que receberam o inseticida. A aplicação impediu o avanço acentuado da praga em todas as parcelas, evidenciando que o controle da lagarta foi benéfico, independentemente do uso dos diferentes volumes e do tipo de ponta. Em média, as parcelas tratadas obtiveram produtividade 7,6\% superior à testemunha. O controle da lagarta resulta em maior área foliar verde remanescente, com consequente manutenção do potencial produtivo. FIGUEIREDO et al. (2006), avaliando o efeito do inseticida clorpirifós na supressão de Spodoptera frugiperda na cultura do milho, também encontraram boa eficiência de controle, resultando em maior produtividade. 
TABELA 6. Produtividade da cultura do sorgo ( $\mathrm{kg}$ de matéria seca ha $\left.{ }^{-1}\right)$ em função da aplicação de inseticida com diferentes pontas e volumes de calda. Sorghum yield (kg of dry matter $\mathrm{ha}^{-1}$ ) under different spray volumes and nozzles used in insecticide application.

\begin{tabular}{lcc}
\hline \multicolumn{1}{c}{ Ponta } & Tratamento & $\begin{array}{c}\text { Produtividade } \\
\left(\mathrm{kg} \mathrm{ha}^{-1}\right)\end{array}$ \\
\hline JA 2 & Volume de Calda $\left(\mathrm{L} \mathrm{ha}^{-1}\right)$ & $15.460,8^{*}$ \\
TTJ60 110-02 & 130 & $16.522,5^{*}$ \\
TTI 110-02 & 130 & $16.266,8^{*}$ \\
JA 2 & 130 & $15.384,3^{*}$ \\
TTJ60 110-02 & 200 & $16.651,8^{*}$ \\
TTI 110-02 & 200 & $17.054,5^{*}$ \\
\hline Testemunha & 200 & $15.080,3$
\end{tabular}

As médias seguidas por um asterisco diferem significativamente da testemunha, a 5\% de probabilidade, pelo teste de Dunnett.

Neste trabalho, foi avaliada a eficiência do controle de Spodoptera frugiperda, a deposição e cobertura do alvo e a produtividade do sorgo em condições adequadas de aplicação, incluindo temperatura do ar, umidade e velocidade do vento. Contudo, outras condições de aplicação podem existir no campo, podendo trazer como consequência redução na eficiência de controle. Daí a importância do monitoramento das condições climáticas durante as aplicações.

\section{CONCLUSÕES}

As pontas de jato plano defletor duplo e jato plano defletor com indução de ar proporcionaram maior cobertura do dossel inferior e superior das plantas de sorgo do que a ponta de jato cônico vazio, resultando em maior eficácia de controle de Spodoptera frugiperda e maior produtividade. O volume de calda de $200 \mathrm{~L} \mathrm{ha}^{-1}$, quando comparado ao volume de $130 \mathrm{~L} \mathrm{ha}^{-1}$, também proporcionou melhor eficácia de controle. O emprego do inseticida proporciou maior produtividade em todas as parcelas que receberam o produto, independentemente da forma de aplicação.

\section{REFERÊNCIAS}

AZEVEDO, R.; GRÜTZMACHER, A. D.; LOECK, A. E.; SILVA, F. F.; STORCH, G.;

HERPICH, M. I. Efeito do tratamento de sementes e aplicações foliares de inseticidas em diferentes volumes de calda, no controle de Spodoptera frugiperda, nas culturas do milho e sorgo em agroecossistema de várzea. Revista Brasileira de Agrociência, Pelotas, v.10, n.1, p.71-77, 2004.

BOLLER, W.; MACHRY, M. Efeito da pressão de trabalho e de modelos de pontas de pulverização sobre a eficiência de herbicida de contato em soja. Engenharia Agrícola, Jaboticabal, v.27, n.3, p.722-727, 2007.

CUNHA, J.P.A.R.; MOURA, E.A.C.; SILVA JÚNIOR, J.L.; ZAGO, F.A.; JULIATTI, F.C. Efeitos de pontas de pulverização no controle químico da ferrugem da soja. Engenharia Agrícola, Jaboticabal, v.28, n.2, p.283-291, 2008.

CUNHA, J.P.A.R.; REIS, E.F.; SANTOS, R.O. Controle químico da ferrugem asiática da soja em função de ponta de pulverização e de volume de calda. Ciência Rural, Santa Maria, v.36, n.5, p.1.360-1.366, 2006.

CUNHA, J.P.A.R.; TEIXEIRA, M.M.; VIEIRA, R.F.; FERNANDES, H.C.; COURY, J.R. Espectro de gotas de bicos de pulverização hidráulicos de jato plano e de jato cônico vazio. Pesquisa Agropecuária Brasileira, Brasília, v.39, n.10, p.977-985, 2004.

FIGUEIREDO, M.L.C.; MARTINS-DIAS, A.M.P.; CRUZ, I. Efeito do inseticida chlorpyrifos e sua interação com inimigos naturais na supressão de Spodoptera frugiperda (J.E. Smith, 1797) 
(Lepidóptera: Noctuidae) na cultura do milho. Revista Brasileira de Milho e Sorgo, Sete lagoas, v.5, n.3, p.325-339, 2006.

GONTIJO NETO, M.M.; OBEID, J.A.; PEREIRA, O.G.; CECON, P.R.; CANDIDO, M.J.D.; MIRANDA, L.F. Híbridos de sorgo (Sorghum bicolor (L.) Moench) cultivados sob níveis crescentes de adubação: rendimento, proteína bruta e digestibilidade in vitro. Revista Brasileira de Zootecnia, Viçosa - MG, v.31, n.4, p.1.640-1.647, 2002.

HENDERSON, C.F.; TILTON, E.W. Tests with acaricides against the brown wheat mite. Journal Economic Entomology, Lanham, v.48, n.2, p.157-161, 1955.

NASCIMENTO, W.G.; PRADO, I.N.; JOBIM, C.C.; EMILE, J.C.; SURAULT, F.; HUYGUE, C. Valor alimentício das silagens de milho e de sorgo e sua influência no desempenho de vacas leiteiras. Revista Brasileira de Zootecnia, Viçosa - MG, v.37, n.5, p.896-904, 2008.

NUYTTENS, D.; BAETENS, K.; DE SCHAMPHELEIRE, M.; SONCK, B. Effect of nozzle type, size and pressure on spray droplet characteristics. Biosystems Engineering, London, v.97, n.3, p.333-345, 2007.

SERRA, M.E.; CHAIM, A.; RAETANO, C.G. Pontas de pulverização e eletrificação das gotas na deposição da calda em plantas de crisântemo. Pesquisa Agropecuária Brasileira, Brasília, v. 43, n.4, p.479-485, 2008.

SILVA, M.T.B. Fatores que afetam a eficiência de inseticidas sobre Spodoptera frugiperda Smith em milho. Ciência Rural, Santa Maria, v.29, n.3, p.383-387, 1999.

ZHU, H.; DORNER, J.W.; ROWLAND, D.L.; DERKSEN, R.C.; OZKAN, H.E. Spray penetration into peanut canopies with hydraulic nozzle tips. Biosystems Engineering, London, v.87, n.3, p.275283, 2004. 